\title{
READ MY LIPS: \\ THE POLITICAL ECONOMY OF INFORMATION TRANSMISSION
}

by

Timothy Besley and Rohini Pande

London School of Economics and Political Science

Contents:

Abstract

1. Introduction

2. The Model

3. Full Information

4. Incomplete Information

5. Political Economy and Welfare Analysis

6. Discussion

7. Concluding Comments

References

8. Proofs

Discussion Paper

No.TE/98/355

July 1998
Theoretical Economics Workshop

The Suntory Centre

Suntory and Toyota International Centres for Economics and Related Disciplines London School of Economics and Political Science Houghton Street London WC2A 2AE Tel.: 0171- 4057686 


\begin{abstract}
The paper studies credible information transmission by governments. A group of heterogenous individuals have to make private investment and labour supply decisions while relying on the government for information about investment returns. The government consists of an elected citizen who chooses a redistributive strategy in addition to providing information. We give conditions under which the outcome leads to overor under-investment in high return activities and the outcome is Pareto efficient.
\end{abstract}

Keywords: Political economy; cheap talk; redistribution; development. JEL Nos.: H10, D82, H23, O12.

(C) by Timothy Besley and Rohini Pande. All rights reserved. Short sections of text, not to exceed two paragraphs, may be quoted without explicit permission provided that full credit, including (C) notice, is given to the source. 


\section{Introduction}

One of basic tenets of public economics is that pure public goods should be provided by governments. Information of common interest to citizens, such as public safety announcements, seem like a clear cut application of this principle. In some countries, this aspect of government intervention is taken much further. For example, the direction of investment strategies of private firms is often associated with the economic success of East Asia. Indeed Japan's Ministry of International Trade and Industry is often held up as a paragon of indicative planning where firms were encouraged to invest in leading sectors. ${ }^{1}$ Unquestioning adherence to the view that governments should act as knowledge banks for their citizens does, however, require that they face no agency problems in deciding what to reveal. This paper analyzes how the power to redistribute can interfere with incentives for credible information transmission and can lead to political failure in the transmission of information. We consider a model where private sector investment decisions could be informed by information available to the government. However, citizens must rely on politicians elected to carry out redistributive strategies to make announcements. In some cases identified here, this leads to under-exploitation of profitable investment opportunities and Pareto inefficiency.

The analysis is related to the growing literature that incorporates imperfect information into political economy models, some of which consider the role of cheap talk. We suppose that the policy maker is privately informed. This is a common informational assumption in the extensive literature on political agency models — see, for example, Rogoff (1990) who demonstrates how costly signalling on the part of governments to affect re-election probabilities can result in political business cycles. In contrast, we focus on costless signaling. Stein (1989)'s analysis of cheap talk by a central bank is related to this paper. He suggests that limits on credible information transmission explain why organizations like the Federal Reserve may make only imprecise policy announcements.

\footnotetext{
${ }^{1}$ MITI has been responsible for Japan's industrial policy post World War II . Conventional wisdom is that industrial policy as determined by MITI played an important role in Japan's subsequent growth performance (See for instance, World Bank (1993)). One of MITI's primary functions was to provide information to the private sector via deliberation councils which had members from the Japanese government and the Private sector. Firms could choose to not heed MITI's advice, the creation of the Mitsubishi Automobile company in 1965 against MITI's advice is a case in point.
} 
Recent electoral models have focused on situations where some citizens are better informed than others prior to an election. This approach includes the recent work by Feddersen and Pesendorfer (1996) on how well voting aggregates information. Grossman and Helpman (1997) allow for the possibility of imperfectly informed voters being swayed by special interest group endorsements which take the form of cheap talk. Banerjee and Somanathan (1997) consider the role of cheap talk in a world in which citizens enjoy an informational advantage. However, rather than modeling elections, they consider the possibility of direct reports of the state of the world to an uninformed policy maker. They demonstrate why only certain kinds of citizens get the ear of policy makers and hence are influential in the policy process.

Other papers have focused on how legislative processes may be affected by communication. Gilligan and Krehbiel (1989) and Austen-Smith (1990) focus on how strategic pronouncements by committees can influence legislation passed on the floor of a legislature. In similar spirit, Matthews (1989) considers how rhetoric (modeled as cheap talk) can affect policy outcome in an environment where a president with veto power faces a legislature which is imperfectly informed about the president's type.

Many of these contributions build on Crawford and Sobel's (1982) seminal work on strategic information transmission. They showed how diversity in preferences between a sender and receiver limits the amount of information that can be credibly conveyed. In comparison, in our paper, the extent of preference diversity is endogenous. The policy maker and hence message sender is elected. Our model embeds the cheap talk game in an explicit economic environment where individuals make private investment and labor supply decisions and governments redistribute. This allows for a clear distinction between the issues of how much information is revealed in equilibrium and whether investment outcomes are inefficient in a conventional Paretian sense. We show that (lack of) revelation of information is a distinct issue from whether the outcome can be Pareto dominated.

We embed our game of information transmission in a model where citizens are uncertain about the value of particular investment strategies and rely on the government to advise them on this. After receiving government advice the investment decisions are made. Finally, the government can choose to redistribute income across groups. We demonstrate how the possibility of redistribution is responsible for how credibly governments transmit information - a government that cannot redistribute or has no desire to do so faces no credibility problem in our model. The choice of the citizen who 
transmits information and makes redistributive decisions is determined in an election. This provides a simple way of making the policy choice and information transmission decision endogenous. We use the model to identify when it is possible to have a Pareto dominated policy choice selected in political equilibrium.

The remainder of the paper is organized as follows. The next section lays out the model. Section three considers the complete information case, while section four extends this to incomplete information. Section five discusses political economy and welfare issues in the model. Section six discusses some possible extensions and implications of the results. Section seven concludes.

\section{The Model}

The economy consists of $N$ citizens indexed by $i \in\{1, . ., N\}$ and lasts one period. There are two productive sectors in the economy, indexed by $\ell \in$ $\{A, B\}$. Each citizen is endowed with one unit of capital and one unit of labor. We assume that an individual can only supply his labor in his own sector at a wage rate $w_{\ell} \in\left\{w_{A}, w_{B}\right\}$ and that $w_{B}>w_{A}$. On the other hand, capital can be invested indivisibly in either sector, where $k_{i}=1$ denotes that individual $i$ invests in sector $A$ and $k_{i}=0$ denotes investment in sector $B$. The return to capital in sector $\ell$ is denoted $r_{\ell j}$, where $j$ denotes the state of the world.

There are four possible states of the world, two of which favor sector $A$ and two of which favor sector $B$. A base return $\bar{r}$ is guaranteed in every state. However, an additional incremental return may also be available. These increments are denoted $\left\{\Delta_{H}, \Delta_{L}\right\}$ with $\Delta_{H}>\Delta_{L}$ and

$$
\begin{aligned}
& r_{A 1}=\bar{r}+\Delta_{H}>r_{B 1}=\bar{r} \\
& r_{A 2}=\bar{r}+\Delta_{L}>r_{B 2}=\bar{r} \\
& r_{B 3}=\bar{r}+\Delta_{L}>r_{A 3}=\bar{r} \\
& r_{B 4}=\bar{r}+\Delta_{H}>r_{A 4}=\bar{r}
\end{aligned}
$$

Hence, in states 1 and 2 sector $A$ is favored and in states 3 and 4 sector $B$ is favored. While a citizen can invest in either sector, we suppose that it is cheaper to invest in one's own sector. We suppose that this is due to unmodelled monitoring costs denoted by $\delta$. A key assumption that we maintain throughout the analysis is 
Assumption 1: $\Delta_{H}>\delta>\Delta_{L}>0$.

This implies that the returns are sufficient to cover the transaction cost of investing out of sector only if the return is $\Delta_{H}$. Thus it is not enough to know which sector is favored - it is necessary to know by how much.

We allow the government to intervene in the economy by redistributing income. We suppose that it does so by levying an income tax and redistributing the proceeds back to the citizens in lump sum form. The parameters of the tax system are therefore an income tax rate $t \in[0,1]$ and an income guarantee level $T \in \Re$. While this is a simplistic picture of real world redistributive strategies, it suffices to make the main points of this paper. We assume that the tax base does not allow investors to deduct their cross sectoral investment monitoring costs from their taxable income. This seems reasonable given many of these are likely to be non-pecuniary costs.

The preferences of a citizen $i$ located in sector $A$ in state $j$ are

$$
(1-t)\left[w_{A} l+r_{A j} k_{i}+r_{B j}\left(1-k_{i}\right)\right]-\phi(l)-\delta\left(1-k_{i}\right)+T
$$

where $\phi(\cdot)$ is a common disutility of labor function which we suppose to be smooth, increasing and convex. For citizen $i$ located in sector $B$ preferences are

$$
(1-t)\left[w_{B} l+r_{A j} k_{i}+r_{B j}\left(1-k_{i}\right)\right]-\phi(l)-\delta k_{i}+T
$$

It is clear that the optimal labor supply in either sector is

$$
l_{i}^{*}=\arg \max \left\{(1-t) w_{\ell} l-\phi(l): l \in[0,1]\right\} .
$$

Let $v\left((1-t) w_{\ell}\right)=(1-t) w_{\ell} l_{i}^{*}-\phi\left(l_{i}^{*}\right)$ and define

$$
\begin{aligned}
V_{j}^{A}\left(w_{A}, k_{i}, t, T\right)= & v\left((1-t) w_{A}\right)+ \\
& (1-t)\left[r_{A j} k_{i}+r_{B j}\left(1-k_{i}\right)\right]-\delta\left(1-k_{i}\right)+T
\end{aligned}
$$

and

$$
\begin{aligned}
V_{j}^{B}\left(w_{B}, k_{i}, t, T\right)= & v\left((1-t) w_{B}\right)+ \\
& (1-t)\left[r_{A j} k_{i}+r_{B j}\left(1-k_{i}\right)\right]-\delta k_{i}+T
\end{aligned}
$$

as the indirect utility function of a representative individual in each sector. Individuals may be imperfectly informed about the true state of the world. In this case let $q_{j}$ be the (commonly held) probability that the state is $j$. Their ex ante expected utility is thus $\sum_{j=1}^{4} q_{j} V_{j}^{\ell}\left(w_{\ell}, k_{i}, t, T\right)$. 
Given a particular state of the world and a particular vector of investment decisions is realized, we can define the vector of ex post feasible tax and transfer policies in state $j$. These will satisfy the following government budget constraint.

$$
\begin{aligned}
& N T=t\left[\left(\sum_{i=1}^{N} k_{i}\right) r_{A j}+\left[N-\sum_{i=1}^{N} k_{i}\right] r_{B j}+\right. \\
& \left.w_{A} N_{A} l_{A}^{*}\left((1-t) w_{A}\right)+w_{B} N_{B} l_{B}^{*}\left((1-t) w_{B}\right)\right]
\end{aligned}
$$

Defining $k=\left(k_{1}, \ldots, k_{N}\right)$, let $Z_{j}(k)$ denote the set of $(t, T)$ pairs that satisfy this equation.

\section{Full Information}

We begin by studying equilibrium investment and policy decisions under full information about the state. The timing is as follows. First, nature selects the state which is observable to all. Second, individuals make investment decisions. Finally, government chooses a redistributive policy after which each individual chooses his/her labor supply. We are interested in the case where individuals cannot influence government policy through their private sector actions. This is true if the government budget constraint is independent of $i$ 's decision. Hence, we consider a large $N$ where the fractions $N_{A} / N$ $\left(\equiv \pi_{A}\right)$ and $N_{B} / N\left(\equiv\left(1-\pi_{A}\right)\right)$ are fixed, and $\pi_{A} \in[0,1]$. We focus on the case where everyone within a sector behaves symmetrically. In that case we can think of an investment strategy for a representative member of sector $\ell$ denoted $K_{\ell}$, with $K_{\ell}=1$ denoting the case where members of sector $\ell$ invest in sector $A$ and $K_{\ell}=0$ denoting the case where sector $\ell$ members invest in sector $B$. Let $K=\left(K_{A}, K_{B}\right)$ represent the aggregate sector investment decisions.

To solve the model, we work backwards. Consider the preferences

$$
G_{j}(\gamma, K, t, T,)=\gamma V_{j}^{A}\left(w_{A}, K_{A}, t, T\right)+(1-\gamma) V_{j}^{B}\left(w_{B}, K_{B}, t, T\right) .
$$

These represent a weighted sum of the two sector's utilities. In a political economy model, we will argue that we expect either $\gamma=1$ or $\gamma=0$ to determine the redistributive decision. However, for the moment it is useful to keep $\gamma$ as a parameter. As $\gamma$ varies, we map the entire set of ex post Pareto optimal tax and transfer policies. Define

$$
\left(t_{\gamma j}^{*}(K,), T_{\gamma j}^{*}(K)\right)=\underset{(t, T)}{\arg \max } G_{j}(\gamma, K, t, T)
$$




$$
\begin{aligned}
& \text { subject to } \\
& (t, T) \in Z_{j}(K)
\end{aligned}
$$

as the optimal choice of redistributive policy for a particular state, investment profile and social preference. Since, in our large economy, $K$ depends only on the fractions of individuals who invest, individuals will treat the redistributive policy as independent of their own investment decision.

It is now straightforward to characterize the equilibrium investment decisions for this economy. Under full information, it is clear that the optimal investment decision of an individual in sector $\ell \in\{A, B\}$ solves

$$
K_{\ell j}^{*}\left(t_{j}, T_{j}\right)=\underset{K_{\ell} \in\{0,1\}}{\arg \max }\left\{V_{j}^{\ell}\left(w_{\ell}, K_{\ell}, t_{j}, T_{j}\right)\right\} .
$$

In this formulation, individuals take the tax policy as given. Note, however, that for high enough levels of redistributive taxation, individuals can be prevented from seeking to invest anywhere outside their own sector. An investment equilibrium solves

$$
\widehat{K}_{\ell j}=K_{\ell j}^{*}\left(t_{\gamma j}^{*}\left(\widehat{K}_{j}\right), T_{\gamma j}^{*}\left(\widehat{K}_{j}\right)\right) \ell \in\{A, B\} .
$$

where $\widehat{K}_{j}=\left(\widehat{K}_{A j}(\gamma), \widehat{K}_{B j}(\gamma)\right)$. We assume that this exists and is unique.

We can now state our notion of equilibrium. The outcome of the model is a particular tax, redistribution and investment profile in each state. Formally, denote this as an investment and redistribution sequence (IRS) $\left\{t_{j}, T_{j}, K_{j}\right\}_{j=1}^{4}$. Then, a $\left\{t_{j}, T_{j}, K_{j}\right\}_{j=1}^{4}$ can be generated as an equilibrium IRS if and only if there is some $\gamma \in[0,1]$, such that (i) $\left(t_{j}, T_{j}\right)$ can be generated from (2) given $K_{j}$ and (ii) $K_{j}$ can be generated as an investment equilibrium.

Since payoffs depend on the IRS, we are interested in what different IRS's can be generated as we vary the preferences of the policy maker. To start with we consider when such a sequence has no redistribution. In this case, under assumption 1, the optimal investment strategies are

$$
\begin{aligned}
& K_{A j}^{*}(0,0)=1 \text { for } j=1,2,3 \text { and } K_{A 4}^{*}(0,0)=0 \\
& K_{B 1}^{*}(0,0)=1 \text { and } K_{B j}^{*}(0,0)=0 \text { for } j=2,3,4 .
\end{aligned}
$$

Without redistribution, it is trivial that these form an investment equilibrium. The monitoring costs make investment decision conservative - individuals favor their own sector unless there is an outstanding opportunity in 
the other sector. For this to be part of an IRS that can be generated as an equilibrium of the model, we need to show that this can be generated by actual government and investor behavior. Hence, we consider when zero redistributive taxation will be a Pareto optimal choice in this model.

Throughout the analysis, we suppose that citizens in sector $B$ have higher wages than those in sector $A$. This means that sector $A$ individuals will, on the whole, desire to redistribute via the income tax. The only possible exception is if sufficient inequality is generated by the different investment strategies pursued in each sector. Specifically, in state 2 where sector $B$ individuals do not desire to invest in sector $A$, while sector $A$ individuals earn an extra return of $\Delta_{L}$ by investing in their own sector, this will tend to reduce ex post inequality and may even generate an incentive for sector $B$ individuals to redistribute income. For ease of exposition, we rule this out by assumption. Specifically, we make

\section{Assumption 2:}

$$
\begin{aligned}
v\left((1-t) w_{B}\right)+ & t\left[\pi_{A} w_{A} l_{A}^{*}\left((1-t) w_{A}\right)+\left(1-\pi_{A}\right) w_{B} l_{B}^{*}\left((1-t) w_{B}\right)\right] \\
& +t \pi_{A} \Delta_{L} \text { is decreasing in } t .
\end{aligned}
$$

As Sector B individuals earn a higher wage, the first two terms are always decreasing in $t$. Assumption 2 ensures that any redistributive gains accruing to sector B in $s_{2}$ due to sector A individuals higher investment returns does not offset their loss from redistribution as represented by the first two terms. This will be true provided that the wage difference between the sectors is sufficiently large and/or $\Delta_{L}$ is sufficiently small.

For the rest of the analysis we assume that Assumption 2 holds. Assumption 2 provides us with a simple characterization of tax policies that favor sector $B$ and the associated investment strategies. These are given in

Proposition 1 With $\gamma=0$, there is a unique $\operatorname{IR} S\left\{t_{j}, T_{j}, K_{j}\right\}_{j=1}^{4}$ that can be generated as an the equilibrium of the model where (i) there is no redistribution in any state and (ii) investment decisions are generated by (4).

Assumption 2 implies that a policy maker who maximizes the payoff of sector $B$ citizens will never choose to redistribute. Therefore, investment will be as in the full information, no redistribution situation.

We now study the case where $\gamma=1$, so that the tax policy reflects the preferences of citizens in sector $A$. It is useful to define 


$$
\begin{gathered}
\bar{t}(\mu)={ }_{t \in[0,1]}^{\arg \max }\left\{v\left((1-t) w_{A}\right)+t\left[\pi_{A} w_{A} l_{A}^{*}\left((1-t) w_{A}\right)+\right.\right. \\
\left.\left.\left(1-\pi_{A}\right) w_{B} l_{B}^{*}\left((1-t) w_{B}\right)\right]+t \mu\right\}
\end{gathered}
$$

as the tax rate desired by an individual in sector $A$. Let

$$
\bar{T}(\mu)=\bar{t}(\mu)\left[\pi_{A} w_{A} l_{A}^{*}\left((1-\bar{t}(\mu)) w_{A}\right)+\left(1-\pi_{A}\right) w_{B} l_{B}^{*}\left((1-\bar{t}(\mu)) w_{B}\right)+\mu\right]
$$

be the associated transfer at this tax rate. In the case where $\mu=0$, we just have the standard model where wage inequality drives the desire to redistribute. The parameter $\mu$ represents the possibility that incentives to redistribute are affected by disparities in income due to asymmetric investment strategies across sectors. For example, in state 3 there is an extra redistributive incentive because sector $B$ individuals earn an additional $\Delta_{L}$ by investing in their own sector, compared to the sector $A$ individuals who invest in their own sector. A very useful assumption which we maintained throughout is

Assumption 3: $(1-\bar{t}(0)) \Delta_{H}>\delta$.

While it would be straightforward to relax this, its value comes from the benchmark that it allows us to establish. The assumption says that, at the level of redistributive taxation at which both sectors make the same investment decisions, it is worthwhile to invest in the other sector when the return there is $\Delta_{H}$. This assumption will hold provided that inequality is not too great and/or there is a sufficiently steep labor schedule to hold redistributive sentiments by sector $A$ individuals in check. We can now prove:

Proposition 2 With $\gamma=1$, there is a unique $\operatorname{IRS}\left\{t_{j}, T_{j}, K_{j}\right\}_{j=1}^{4}$ that can be generated as an the equilibrium of the model where

(i) the redistributive strategies are

$$
\begin{array}{r}
\left(t_{j}, T_{j}\right)=(\bar{t}(0), \bar{T}(0)) \text { for } j=1,4, \\
\left(t_{2}, T_{2}\right)=\left(\bar{t}\left(-\left(1-\pi_{A}\right) \Delta_{L}\right), \bar{T}\left(-\left(1-\pi_{A}\right) \Delta_{L}\right)\right) \\
\left(t_{3}, T_{3}\right)=\left(\bar{t}\left(\left(1-\pi_{A}\right) \Delta_{L}\right), \bar{T}\left(\left(1-\pi_{A}\right) \Delta_{L}\right)\right)
\end{array}
$$

and

(ii) the investment decisions are identical to those found without redistribution. 
The first part details the redistribution decisions in each state of the world. This mirrors the underlying wage inequality plus any changes in income distribution due to asymmetric investment strategies in the two sectors. The second part gives the investment equilibrium. The main observation is that this is identical to that under zero redistribution. Assumption 3 is critical to this finding and allows us to have a simple full information investment benchmark against which to contrast incomplete information. Since the desire for redistribution is increasing in $\gamma$, a corollary of these two propositions is that, under assumptions 2 and 3, every ex post Pareto optimal redistribution schedule has the same investment profile. This is true in spite of the fact that we have not allowed the policy maker to commit to redistribution in advance. In this benchmark case, equilibrium redistribution affects labor supply decisions, but not investment.

\section{Incomplete Information}

We now consider a world in which only the policy maker knows the true state of the world. As we argued above, this fits a number of relevant contexts. The government can transmit information costlessly to the citizens, i.e. it is cheap talk. The citizens listen to these messages and update their beliefs taking into account the credibility of the statements that they hear.

The timing of the model is now as follows. First, nature determines the state which is observed only by the policy maker. The policy maker can then transmit a message to the other citizens. On the basis of this, citizens choose simultaneously how to invest. After investment, the state of nature is revealed to all citizens. The policymaker then chooses a redistributive strategy. Finally, payoffs are realized.

The policy choice will satisfy (2). The investment profile depends upon investors' beliefs about which state of the world has obtained. We assume investors in all sectors have identical priors and denote these by $\left\{p_{j}\right\}_{j=1}^{4}$. After receiving a message about which state of the world has occurred, investors' posterior probabilities are $\left\{q_{j}\right\}_{j=1}^{4}$. We focus on symmetric investment strategies, where investors take the redistributive policy associated with each state of the world as given. Let

$$
\widetilde{K}_{\ell}\left(q ;\left\{t_{j}, T_{j}\right\}_{j=1}^{4}\right)=\underset{k \in\{0,1\}}{\arg \max } \sum_{j=1}^{4} q_{j} V_{j}^{\ell}\left(w_{\ell}, k_{i}, t_{j}, T_{j}\right)
$$


be the optimal investment decision for an investor in sector $\ell$. An investment equilibrium $\left(\widehat{K}_{A}(\gamma, q), \widehat{K}_{B}(\gamma, q)\right)$ solves

$$
\widehat{K}_{\ell}=\widetilde{K}_{\ell}\left(q,\left\{t_{\gamma j}^{*}(\widehat{K}), T_{\gamma j}^{*}(\widehat{K})\right\}_{j=1}^{4}\right) \ell \in\{A, B\} .
$$

Let

$$
\widehat{K}(\gamma, q)=\left(\widehat{K}_{A}(\gamma, q), \widehat{K}_{B}(\gamma, q)\right)
$$

be the investment equilibrium for some beliefs $q$ about the state of the world. Once again, we assume that this is unique.

We assume that absent further information (beyond an individual's priors) about which state has occurred, the investment equilibrium has each individual investing in their own sector. Formally, we make

Assumption 4: $\widehat{K}_{A}(0, p)=1$ and $\widehat{K}_{B}(0, p)=0$ for all $\gamma \in[0,1]$.

This is a joint assumption on the prior beliefs and the tax rates in different states. There is no simple way of stating the condition in terms of the primitives. $^{2}$

Beliefs about which state has occurred can depend upon messages sent by the policy maker before investment decisions are taken. A message, denoted $m$, is restricted to belong to a set $\mathcal{M}$ containing all possible subsets of the states. These messages require interpretation by the investors. We assume that the interpretation or beliefs is described by a function $\sigma_{j}(m)$ which denotes the probability that the state is $j$ for any message $m \in \mathcal{M}$. These beliefs are admissible if $\sum_{j=1}^{4} \sigma_{j}(m)=1$ for all messages $m \in \mathcal{M}$. We suppose that the investors update using Bayes rule given the beliefs about the meaning of messages, i.e.

$$
q_{j}(m, p, \sigma)=\frac{p_{j} \sigma_{j}(m)}{\sum_{j=1}^{4} p_{j} \sigma_{j}(m)}
$$

Let $q(m, p ; \sigma)$ denote the vector of posterior beliefs and let

\footnotetext{
${ }^{2}$ Essentially, it requires that

$$
\begin{gathered}
\mid\left(\left(1-t_{1}\right) p_{1}-\left(1-t_{2}\right) p_{4}\right) \Delta_{H} \\
+\left(\left(1-t_{2}\right) p_{2}-\left(1-t_{3}\right) p_{3}\right) \Delta_{L} \mid<\delta,
\end{gathered}
$$
}

where the vector of tax rates satifies (2) at the investment equilibrium, for all $\gamma \in[0,1]$. 


$$
\widehat{G}_{j}(\gamma, q)=G_{j}\left(\gamma, \widehat{K}(\gamma, q), t_{\gamma j}^{*}(\widehat{K}(\gamma, q)), T_{\gamma j}^{*}(\widehat{K}(\gamma, q))\right)
$$

denote the "policy makers" payoff at a particular investment equilibrium. The policymaker optimizes in his choice of messages given $\sigma$, that is

$$
m_{j}^{*}(\sigma) \in \underset{m \in \mathcal{M}}{\arg \max }\left\{\widehat{G}_{j}(\gamma, q(m, p ; \sigma))\right\},
$$

The outcome of the model is a particular tax, redistribution, investment and message profile in each state. We call this an investment, redistribution and message sequence (IRMS) and denote it by $\left\{t_{j}, T_{j}, K_{j}, m_{j}\right\}_{j=1}^{4}$. Then, an IRMS $\left\{t_{j}, T_{j}, K_{j}, m_{j}\right\}_{j=1}^{4}$ can be generated by an equilibrium of the model if and only if, there is a set of admissable beliefs $\sigma$ such that (i) $\left(t_{j}, T_{j}\right)$ satisfies (2) given $K_{j}$, (ii) $K_{j}$ is an investment equilibrium when $q$ is derived from $p$ using Bayes rule, the beliefs $\sigma$ and the messages $m$, and (iii) messages solve (9) in each state given $\sigma$.

As is usual in such models, the fact that many different beliefs are possible about the meaning of messages implies that the signalling equilibrium will not be unique. There is always a trivial equilibrium where no information is transmitted ${ }^{3}$ and citizens invest entirely on their priors. We will focus on cases where beliefs allow us to get as close as possible to a full information investment equilibrium.

We now consider the IRMS's generated by the most informative equilibria under different assumptions about the redistributive preferences of the policy maker. We begin with the most straightforward case where $\gamma=0$. In this case, we have:

Proposition 3 With $\gamma=0$, there exists a set of admissable beliefs $\sigma$ for which an IRMS $\left\{t_{j}, T_{j}, K_{j}, m_{j}\right\}_{j=1}^{4}$ can be generated as an equilibrium of the model with no redistribution, full information revelation and investment decisions given by (4).

Thus a policy maker without redistributive intentions can credibly reveal the information to his citizens. It is easy to see why. A policy maker who cares about sector $B$ individuals care that they invest the right way and has no reason not to reveal the truth to sector $A$ individuals when their investment can benefit from it. The policy maker's incentives do not diverge from those of the citizens.

\footnotetext{
${ }^{3}$ If $\sigma_{j}(m)=\frac{1}{4}$ for all $j$ and all $m \in M$, then we have a babbling equilibrium.
} 
The more interesting case arises where $\gamma=1$ and the policy maker favors sector $A$ individuals. The following preliminary observation says that full information is not a possibility in this instance.

Lemma 1 Suppose that $\gamma=1$, and let $\left(q, q^{\prime}\right)$ be such that $\widehat{K}_{B}(1, q)>$ $\widehat{K}_{B}\left(1, q^{\prime}\right)$, then, for any beliefs $\sigma$, there is no $\left\{m_{j}^{*}\right\}_{j=1}^{4}$ which satisfies (9) such that $q\left(m_{1}^{*}, p, \sigma\right)=q$ and $q\left(m_{2}^{*}, p, \sigma\right)=q^{\prime}$.

This lemma tells us that there cannot be an equilibrium of the message game that leads sector $B$ individuals to invest in sector $A$ in state 1 and not in state 2 . However, full information strategies require sector $B$ individuals to invest in sector $A$ in state 1 , but not in state 2 . This is explained by the policy maker's desire to redistribute. In state 2 , the policy maker who favors sector $A$ always has an incentive to dishonestly announce that state 1 has occurred in order to benefit from the increased transfers that he will receive if a sector $B$ individual invests in sector $A$. Thus having a policy maker who favors sector $A$ cannot result in full information being revealed to investors.

To explore this further, we distinguish between two cases, referred to as the over-investment and under-investment cases. In the over-investment case, sector $B$ individuals invest in sector $A$ even though they sometimes make a loss by doing so, while in the under-investment case, they are conservative and always choose to invest in their own sector. The critical condition that differentiates these two is whether $(1-\bar{t}(0))\left[p_{1} \Delta_{H}+\left(1-p_{2}\right) \Delta_{L}\right]_{<}^{>}\left(p_{1}+p_{2}\right) \delta$. For the over-investment case, we have the following result. ${ }^{4}$

Proposition 4 Suppose that $(1-\bar{t}(0))\left[p_{1} \Delta_{H}+p_{2} \Delta_{L}\right]>\left(p_{1}+p_{2}\right) \delta$, then with $\gamma=1$ there exists a set of admissable beliefs $\sigma$ for which an IRMS $\left\{t_{j}, T_{j}, K_{j}, m_{j}\right\}_{j=1}^{4}$ can be generated as an equilibrium where

(i) redistribution policies are given by

$$
\begin{array}{r}
\left(t_{j}, T_{j}\right)=(\bar{t}(0), \bar{T}(0)) \text { for } j=1,2,4 \\
\left(t_{3}, T_{3}\right)=\left(\bar{t}\left(\left(1-\pi_{A}\right) \Delta_{L}\right), \bar{T}\left(\left(1-\pi_{A}\right) \Delta_{L}\right)\right)
\end{array}
$$

(ii) the policy maker announces the true state when the state is 3 or 4 , but does not differentiate between states 1 and 2 , i.e., $m_{j}^{*}=j$ for $j=3,4$ and $m_{1}^{*}=m_{2}^{*}=\{1 \cup 2\}$

\footnotetext{
${ }^{4}$ Propositions 3, 4 and 5 describe weak equilibria in the sense that, in the equilibrium that we describe, in some states the policy is indifferent between the posited equilibrium message and some other message.
} 
and

(iii) the investment equilibrium has sector $A$ individuals using their full information investment strategies and sector $B$ individuals investing in sector $A$ in states 1 and 2 and in sector $B$ otherwise.

There are three parts to the Proposition. The first gives the redistributive strategies employed by the policy maker. The second gives the equilibrium messages which are the same in either state 1 or 2 . Thus the true state of the world is not revealed in this case. This is because a policy maker who maximizes the payoff of sector $A$ individuals cannot credibly distinguish between states 1 and 2 . The argument is exactly that developed to prove Lemma 1. Part (iii) of the Proposition gives the investment strategies which lead to over-investment in sector $A$.

We now consider what happens when the tendency is towards to underinvestment in sector $A$. This occurs if $(1-\bar{t}(0))\left[p_{1} \Delta_{H}+p_{2} \Delta_{L}\right]<\left(p_{1}+p_{2}\right) \delta$. The outcome is described in

Proposition 5 Suppose that $(1-\bar{t}(0))\left[p_{1} \Delta_{H}+p_{2} \Delta_{L}\right]<\left(p_{1}+p_{2}\right) \delta$, then with $\gamma=1$ there exists a set of admissable beliefs $\sigma$ such that an IRMS $\left\{t_{j}, T_{j}, K_{j}, m_{j}\right\}_{j=1}^{4}$ can be generated as an equilibrium of the model where

(i) redistributive policies are given by

$$
\begin{array}{r}
\left(t_{1}, T_{1}\right)=\left(\bar{t}\left(-\left(1-\pi_{A}\right) \Delta_{H}\right), \bar{T}\left(-\left(1-\pi_{A}\right) \Delta_{H}\right)\right) \\
\left(t_{2}, T_{2}\right)=\left(\bar{t}\left(-\left(1-\pi_{A}\right) \Delta_{L}\right), \bar{T}\left(-\left(1-\pi_{A}\right) \Delta_{L}\right)\right) \\
\left(t_{3}, T_{3}\right)=\left(\bar{t}\left(\left(1-\pi_{A}\right) \Delta_{L}\right), \bar{T}\left(\left(1-\pi_{A}\right) \Delta_{L}\right)\right) \\
\left(t_{4}, T_{4}\right)=(\bar{t}(0), \bar{T}(0))
\end{array}
$$

(ii) the policy maker announces the true state when the state is 3 or 4, but does not differentiate between states 1 and 2 , i.e., $m_{j}^{*}=j$ for $j=3,4$ and $m_{1}^{*}=m_{2}^{*}=\{1 \cup 2\}$

and

(iii) the investment equilibrium has sector $A$ individuals using their full information investment strategies and sector $B$ individuals investing in sector $B$.

Again, there are three parts. The first gives the redistributive strategies. The second the equilibrium messages. These are identical to those described 
in Proposition 4. The third part give the investment strategies. The key difference with Proposition 4 is that individuals in sector $B$ now never choose to invest in sector $A$, even in state 1.

A comparison of Proposition 3, 4 and 5 shows how a policy maker's ability to credibly transmit information is affected by his redistributive preferences. A policy maker with no desire to redistribute has no credibility problem and generates an IRMS which is the same as the full information outcome. The desire for redistribution creates a kind of externality since individuals benefit from others' decisions to invest directly. If costs of investment are not fully internalized, then this results in a credibility problem. The Propositions identify a key condition determining whether the most informative equilibrium under incomplete information has too much or too little investment in sector $A$ compared to the case of full information. We will see below that this has important implications for the welfare analysis. ${ }^{5}$

\section{Political Economy and Welfare Analysis}

So far, we have taken policy maker preferences as exogenous. We now consider what would happen if we allow the identity of the policy maker to be determined in an election. The model that we use for this is the citizen candidate approach developed in Osborne and Slivinski (1996) and Besley and Coate (1997). This is a natural model to consider here where we think of the policy maker as one among the citizens located in sector $A$ or $B$.

The citizen candidate model has three main stages of political competition. At stage one, any citizen can declare him or herself a candidate for office at a small cost $c$. At stage two, voters vote over the declared candidates and at stage three policy is chosen. We suppose that the default policy if nobody enters is $t=0, T=0$ in all states and no messages are sent to the citizens. We also assume that voting and entry decisions are strategic. A political equilibrium is a set of voting decisions at stage two (where no citizen

\footnotetext{
${ }^{5}$ The equilibria in Propositions 4 and 5 do not permit the policy maker to differentiate between states 1 and 2 in the messages that they send. Thus, as in Lemma 1, they do not invoke different investment strategies in these two states. Hence, from an ex post point of view, the outcome generated in these equilibria will be at least as good as any that satisfies Lemma 1. However, from an ex ante view point, it is possible that more informative announcements are possible as long as they lead to the same investment strategy ex post. Since our interest below is in ex post welfare, we do not pursue this possibility further.
} 
uses a weakly dominated strategy) and a set of entry decisions at stage one which form a Nash equilibrium. For details see Besley and Coate (1997).

The last two sections give us a description of what happens in the event that a citizen with a particular type of preference is elected conditional on whether the state of the world is observable to the whole polity. A sector $A$ citizen being elected corresponds to the case where $\gamma=1$ and a sector $B$ sector being elected to the case where $\gamma=0$. The assumption that there are only two types of citizens permits a fairly routine application of Proposition 2 in Besley and Coate (1997). Since (generically) either sector $A$ or sector $B$ citizens are in a majority, we would expect (for small enough $c$ ) a one candidate equilibrium with the candidate representing the preference of the majority sector. If a single candidate of the majority type is standing, no other citizen of the same type would wish to enter - the policy would be unchanged and they would have to pay $c$. No citizen of the non-majority type would wish to enter as in two candidate races where voters do not use weakly dominated voting strategies, the candidate with a majority of sincere preferences will win. In what follows, we assume that $c$ is small enough so that this constitutes the equilibrium.

In a world of complete information, each citizen will prefer to have their own type in office to promote their preferred redistributive policy. The results derived in section 3 imply, that under assumptions 2 and 3, the investment strategies are invariant to which citizen is in office. The only thing decided by political competition is the level of the redistributive taxation. This is like the standard Meltzer and Richards (1981) model of redistribution.

Turning to incomplete information, we observed in Section 4 that the preference of the policy maker affects how much information is revealed and hence equilibrium investment strategies. Our desire to embed the analysis in a model where the policy maker is a citizen generates a further complication since he will also be an investor. Moreover, his investment will always be an informed one, regardless of whether other citizens are also informed by messages that he chooses to send. In a simultaneous move investment game, it would be necessary to separate out the policy maker's informed investment decision from that of his fellow citizens. We do not regard the complications involved in specifying the investment equilibrium for this "asymmetric" case to be worthwhile, in that it does not add anything essential to the analysis of the paper. Hence, we assume that, once elected, a policy maker must place his assets "in trust" which are automatically invested in line with other members of his sector and he earns a return accordingly. Apart from simplifying the 
analysis, this parallels the kind of institutional arrangement that is commonly observed in representative democracies precisely to limit the gains that policy makers can receive by trading on inside information about the future of the economy. ${ }^{6}$ With this assumption, we can use the analysis of the previous section to describe what happens when a type $A$ or $B$ citizen is elected under incomplete information. Specifically, we assume that if a type $B$ policy maker is elected, then the IRMS will be that described in Proposition 3 and if a type $A$ policy maker is elected then the IRMS will be one of those described in Propositions 4 or 5.

It is easy to check that each citizen will still prefer to vote a citizen of their own type in this case. Hence, once again we expect a one candidate equilibrium where the candidate is from the majority sector. If sector $B$ citizens are a majority, then the outcome is that described in Proposition 3 with information fully revealed and no redistribution. If sector $A$ citizens are in the majority, then depending upon whether $(1-\bar{t}(0))\left[p_{1} \Delta_{H}+p_{2} \Delta_{L}\right]-$ $\left(p_{1}+p_{2}\right) \delta$ is positive or negative, either Proposition 4 or 5 will apply.

We know that information is not necessarily revealed in political equilibrium - if a type $A$ citizen is elected to choose policy, then we know that information revelation is only partial while a type $B$ citizen would reveal all information. Less clear is whether full information is ex post Pareto dominant over the political equilibrium. This will be true if there is a feasible tax change such that with the full information investment strategies one of the types of individual can be made strictly better off in some state of the world and no worse off in every other. Since, it generates full information, it is obvious that the outcome when a sector $B$ policy maker chooses policy cannot be Pareto dominated. Hence, we consider whether the equilibrium with a type $A$ policy maker can be dominated by full information revelation coupled with an appropriate variation in tax policy. For the rest of the paper we assume

Assumption 5: Sector A individuals constitute a majority in the population.

Our first result shows that we have already described an equilibrium in which the outcome is Pareto inefficient.

\footnotetext{
${ }^{6}$ In the U.S. the general rule is that top officials must either divest their holdings, or put them in a blind trust. If a top official has not put assets into a blind account, then he or she must definitely be recused from handling matters that affect the value of those assets. It is worth noting that many of these restrictions come from Executive Orders and 'ethics codes' rather than laws.
} 
Proposition 6 Suppose that $(1-\bar{t}(0))\left[p_{1} \Delta_{H}+p_{2} \Delta_{L}\right]<\left(p_{1}+p_{2}\right) \delta$ and the political equilibrium generates the IRMS described in Proposition 5. Then this outcome can be Pareto dominated by the IRMS with full information revelation.

Thus the under-investment case results in a Pareto inefficient outcome. Sector $B$ individuals choose to invest in their own sector regardless of the message that they receive and sector $A$ individuals behave as in a complete information world. The only difference in investment strategies arises in state 1, where with full information the sector $B$ individual would wish to invest in sector $A$. This will be the equilibrium investment strategy under full information for any Pareto efficient tax on income. Clearly, with full information the sector $B$ individuals are better off in state 1 if we keep the tax rate at $\bar{t}\left(-\left(1-\pi_{A}\right) \Delta_{H}\right)$. If $\bar{t}\left(-\left(1-\pi_{A}\right) \Delta_{H}\right)>0$ then Sector $A$ individuals are also better off in state 1 since they get a larger income transfer from the government, for a given tax rate. If $\bar{t}\left(-\left(1-\pi_{A}\right) \Delta_{H}\right)=0$ then Sector $\mathrm{A}$ individuals are indifferent between the two outcomes.

In the over-investment case where $(1-\bar{t}(0))\left[p_{1} \Delta_{H}+p_{2} \Delta_{L}\right]>\left(p_{1}+p_{2}\right) \delta$ holds, then the outcome cannot be Pareto dominated by a situation in which the information about the state of the world is revealed.

Proposition 7 Suppose that $(1-\bar{t}(0))\left[p_{1} \Delta_{H}+p_{2} \Delta_{L}\right]>\left(p_{1}+p_{2}\right) \delta$ and that the political equilibrium generates the IRMS described in Proposition 4. Then this outcome cannot be Pareto dominated by the IRMS with full information revelation.

In this case, full information leads to sector $B$ citizens investing less often in sector $A$. This improves sector $B$ individuals' welfare. However, holding tax rates constant, this implies a loss to sector $A$ individuals. Moreover, there is no variation in taxes that can undo that welfare loss.

Thus, whether we are in the under- or over- investment case is critical. Loosely speaking, overinvestment is more likely when investors are relatively more optimistic about the likelihood of state 1 occurring ( $p_{1}$ is high) and/or the additional investment return from investing in sector $\mathrm{A}$ in state 1 is large. The fact that the outcome cannot be Pareto dominated in the case of over-investment shows that the absence of full information revelation does not necessarily imply inefficiency. Put another way, not revealing informa- 
tion which determines investment decisions could form part of an optimal redistributive strategy for the government. ${ }^{7}$

\section{Discussion}

While we have focused on economy wide redistribution strategies, the point of the paper that credibility of information is affected by redistribution possibilities is a general one. One could, for example, derive similar results in a case where special interests can make transfers to politicians in exchange for limiting information transmission. The recent crisis over the safety of beef in the UK precipitated by a party in government which was traditionally supported by farmers could be thought of along these lines. The key ingredient that drives this model is the possibility of an agency problem among politicians who no longer equate the social cost and benefit of information.

The latter interpretation of our result makes clear that we can also get results similar to those developed here from an externality in the production process. Consider a world without redistribution where the wage rate in each sector depended upon the amount of investment in that sector. Then it would be in the interest of the policy maker, to claim that his/her sector had the highest return to capital in order to benefit from wage externality engendered by increased investment. This would again reduce the scope for credible information transmission. As in the model developed above, rents to earning wage income within a sector are also important. If individuals could move to the sector with the highest wage rate, this would not be a problem.

The desire for income redistribution in our model is borne out of an initial wage inequality across sectors, where the wage inequality reflects ownership of different levels or types of human capital. More generally, we could allow for wealth inequalities across sectors by assuming that individuals in different sectors differ in their ownership of capital. Most of the results could be extended to cover this case. However, additional complications could arise if investment disparities across the sectors made the desire to redistribute in different states of the world sensitive to investment decisions. This seems

\footnotetext{
${ }^{7}$ The result can be viewed as failure of the conditions for production efficiency to hold in the Diamond-Mirrlees (1971) sense. This result requires that the government have a full array of (linear) tax instruments. Here, the fact that $\delta$ cannot be taxed is key. If the government were able to adopt a tax system in which $\delta$ were deducted from income before tax was levied, there would be no possibility of inefficiency in the policy choice.
} 
most likely when sector $A$ individuals are capital rich relative to those in sector $B$ even though the latter enjoy a higher wage rate.

We have cast the problem of this paper as one that arises when the policy maker is elected. However, it should be apparent from section three that even with a social planner incomplete information is a possibility if the planner's preferences favor sector $A$. The main issue is whether it is reasonable to think of a truly benevolent planner suffering from credibility problems. ${ }^{8}$ In the spirit of the literature on time-inconsistent capital taxation, we could interpret our results as saying that a planner may face credibility problems in the transmission of information if he favors a particular group and has redistributive power. For instance, in this model a planner with maximin preferences might yield an IRMS that can be Pareto dominated. However, in the final analysis, planners with credibility problems are probably best thought of as citizens who are elected to choose policy, making the political economy interpretation more palatable.

Assumption 3 in the paper guarantees that some transmission of information can be welfare improving from an ex ante point of view. If this assumption fails, then it is possible that investors in one sector prefer the uninformative "babbling" equilibrium to the more informative equilibria. This is because more information leads sector $B$ citizens to reduce their investment in sector $A$ in certain states of the world. ${ }^{9}$ In such cases, ex ante it is possible that full information does not dominate the uninformative equilibrium for sector $A$ individuals. Since the political equilibrium can always deliver an uninformative outcome, we would not expect to find that political equilibrium is Pareto dominated in such cases.

We have focused here on cheap talk. The existing literature on political agency models focuses on costly signalling on part of the policy maker primarily in order to affect re-election incentives. Coate and Morris (1995) have shown how this may lead to inefficient outcomes when two sources of uncertainty exist. We might expect costly signalling to re-emerge in situations where information transmission is important but governments lack credibility. This may be particularly desirable in situations where the cheap talk equilibrium is Pareto dominated. The British Prime Minister's efforts to eat British beef publicly during the recent public safety scare illustrates

\footnotetext{
${ }^{8} \mathrm{~A}$ fully credible planner could always avoid the inefficiency described in Proposition 6 and could commit to a tax rate with full information that made everyone better off.

${ }^{9}$ The failure of assumption 3 is akin to a failure of monotonicity in the sense discussed in Crawford and Sobel (1982).
} 
this kind of behavior. However, as is well known from such models, the very factors that prevent credible cheap talk may engender distortions in the use of costly signalling. In addition, use of these instruments generates a welfare cost that cheap talk may not suffer from.

The model could be thought of as an argument for trying to write constitutions that uncouple policymakers' private interests from the social interest. A policy maker who received a fixed wage regardless of the state of the economy and was immune to considerations about the level of redistribution would always reveal information faithfully. However, the virtues of such a policy could be, in turn, undermined by possible problems of lobbying and promises of future favors to politicians.

\section{Concluding Comments}

Situations where governments enjoy an informational advantage that is important to private decisions are common. Here, we have developed a simple model of why governments might not be able to transmit credibly all of the information that they possess. We have highlighted how the possibility of redistribution can be key to understanding this, although it is not always true that outcomes with limited information are Pareto inefficient. Our analysis can give a broad hint of when development strategies based on some kind of indicative planning can succeed. Societies where underlying redistributive conflicts are slight seem more likely to be successful when they cast governments in this role. This can be squared with the frequently made observation that the East Asian economies benefitted from their relatively low levels of inequality when embarking on their development strategies.

The analysis suggests possibilities for further research. The possibility that information is withheld in equilibrium somewhat undermines the case for governments to monopolize information collection. In most democracies, we see this task also being undertaken by the press, by independent thinktanks, academics etc. Understanding when private provision of information may dominate government provision would be an interesting extension. Of course, similar issues about credibility arise if the information sources were considered to be partisan. However, this kind of approach is well placed to explain circumstances under which private provision of this public good would then not be a perfect substitute for government provision and when private agencies would arise endogenously. 
The analysis also suggests why functions of government might optimally be horizontally differentiated, with agencies providing information being separated from those that engage in redistribution. Of course, functional separation does not guarantee that political influence could not be exacted upon those charged with information transmission. Nonetheless, to the extent that an ethos of independent impartial transmission of information could be inculcated into certain parts of government, the problems described here could be circumvented. The optimal assignment of powers to different divisions of governments and the missions that they are given merits further consideration. 


\section{References}

[1] Austen-Smith, David, (1990), 'Information transmission in debate', American Journal of Political Science 34: 124-152.

[2] Banerjee, Abhijit and Rohini Somanathan, (1997), 'A Simple Theory of Voice,' typescript.

[3] Besley, Timothy and Stephen Coate (1997), 'An Economic Model of Representative Democracy' Quarterly Journal of Economics, 112(1), 85-114

[4] Coate, Stephen and Stephen Morris, (1995), "On the Form of Transfers to Special Interests," Journal of Political Economy, 103, 1210-1235.

[5] Crawford, Vincent and Joel Sobel, (1982), 'Strategic Information Transmission', Econometrica 50:1431-1451

[6] Diamond, Peter and James Mirrlees (1971), 'Optimal Taxation and Public Production I: Production Efficiency and II: Tax Rules', American Economic Review,61,8-27 and 261-78.

[7] Feddersen, Timothy and Wolfgang Pesendorfer (1996),'The Swing Voter's Curse', American Economic Review, 86(3):408-424.

[8] Gilligan Thomas and Kevin Krehbiel, (1989), 'Asymmetric Information and Legislative Rules with a Heterogenous Committee', American Journal of Political Science, 459-490

[9] Grossman, Gene and Elhanan Helpman, (1997), 'Competing for Endorsements,' typescript.

[10] Matthews, Steven, (1989),'Veto threats: rhetoric in a bargaining game', Quarterly Journal of Economics 104:347-369

[11] Meltzer, Allan H. and Richard, Scott F (1981),'A Rational Theory of the Size of Government', Journal of Political Economy, October , 89(5), pp. $914-27$

[12] Osborne, Martin J. and Al Slivinski (1996), 'A Model of Political Competition with Citizen Candidates', Quarterly Journal of Economics, 111(1), 65-96. 
[13] Rogoff, Kenneth, (1990), 'Equilibrium Political Budget Cycles,' American Economic Review, 80, 21-36.

[14] Stein, Jeremy, (1989), 'Cheap Talk and the Fed: A Theory of Imprecise Policy Announcements,' American Economic Review, 79, 32-42.

[15] World Bank (1993), The East Asian Miracle, Oxford University Press. 


\section{Proofs}

Proof of Proposition 1: With $\gamma=0$, the policy maker chooses $\left(t_{j}^{*}, T_{j}^{*}\right)_{j=1}^{4}$ to maximize $V_{j}^{B}\left(w_{B}, K_{B}, t, T\right)$. Since $w_{B}>w_{A}$ the policy maker chooses $t_{j}^{*}=0$ in every state with assumption 2 guaranteeing that this so in state

2. Thus $\left(t_{j}, T_{j}\right)=\left(t_{0 j}^{*}(K), T_{0 j}^{*}(K)\right)=(0,0)$ for $j=1,2,3,4$. In the investment stage, citizens anticipate no redistribution and given assumption 1 this implies that investment decisions obey (4).

Proof of Proposition 2: With $\gamma=1$, the policy maker chooses $\left(t_{j}^{*}, T_{j}^{*}\right)_{j=1}^{4}$ to maximize $V_{j}^{A}\left(w_{A}, K_{A}, t, T\right)$. Since $w_{A}<w_{B}$ the policy maker has an ex ante motive to redistribute. In states 1 and 4 the investment returns are identical across sectors and $\mu=0$. In state 3 investment favors sector B which raises sectoral inequality, with sector $\mathrm{A}$ citizens receiving $\bar{t}\left(1-\pi_{A}\right) \Delta_{L}$ of the additional sector $B$ investment returns. In state 2 the investment returns favors sector A reducing the incentive to redistribute. Sector A individuals receive $\Delta_{L}+\bar{t}\left(-\left(1-\pi_{A}\right) \Delta_{L}\right)$ of their additional investment return. At the investment stage citizens anticipate the redistribution associated with each state. From assumption 3 we know that in states 1 and 4 , positive redistribution will not prevent citizens from investing in the sector with the highest investment return. In states 2 and 3 citizens continue to invest in their own sector. Therefore individuals maintain the same investment decisions as with no redistributive taxation.

Proof of Proposition 3: Suppose that the beliefs are :

$$
\begin{aligned}
\sigma_{j}\left(m_{j}\right) & =1 \text { for } m_{j}=j \text { for } j=1, . ., 4 \\
\sigma_{j}(m) & =\frac{1}{4} \text { for all } m_{j} \in \mathcal{M} /\{1,2,3,4\} .
\end{aligned}
$$

The belief structure is such that any off-the-equilibrium-path messages are intepreted as uninformative and are clearly admissible. We now that they support the equilibrium described. Assumption 4 says that this will result in individuals investment in their own sectors only. The argument in Proposition 1 allows us to conclude that, under Assumption 2, the optimal redistribution associated with $\gamma=0$ is $\left(t_{j}, T_{j}\right)=\left(t_{0 j}^{*}\left(K_{j}\right), T_{0 j}^{*}\left(K_{j}\right)\right)=(0,0)$ for all $j=1,2,3,4$. Hence citizens anticipate no redistribution on or off the equilibrium path.

Assumption 4 tells us that for any deviation from the messages specified in the statement of the Proposition, individuals will invest in their own sectors 
regardless of the information. Given the beliefs about the meaning of messages, it is clear the investors use their full information investment strategies on the equilibrium path. Hence, to complete the proof, all we need to show is that the policy maker prefers to send the informative message rather than transmitting no information. We show this state-by-state. We first show that no off-the-equilibrium path message is preferred and then that no deviation to another equilibrium message is optimal for the policymaker in any state. We use the fact that in every state of the world the policymaker sets $\left(t_{j}, T_{j}\right)=(0,0)$. With $\gamma=0$, the policymaker chooses messages to maximise the welfare of a representative sector $B$ individual $\left(V_{j}^{B}\left(w_{B}, K_{B}, t, T\right)\right)$.

In state 1 , the policymaker will never deviate to off-the-equilibrium path message as $\Delta_{H}>\delta$ implies that

$$
v\left(w_{B}\right)+r_{A 1}-\delta>v\left(w_{B}\right)+r_{B 1}
$$

where the LHS expression is a Sector B individual's payoff on the equilibrium path and the RHS is the payoff after the posited deviation.

In states $k(=2,3$ and 4$)$ a Sector B individual's payoff is the same on and off the equilibrium path at

$$
v\left(w_{B}\right)+r_{B k}
$$

Therefore, the policymaker is indifferent between sending the informative message and an uninformative one.

Now consider the policymaker's incentives to deviate to other on-theequilibrium-path messages. In state 1 , deviating to announce state 2 or state 3 or state 4 hasoccurred results in the same investment strategy as announcing an off-the-equilibrium-path message. Thus by the inequality in (11) this is never a profitable deviation. Now consider the remaining three states. In state 2 or state 3 or state 4 announcing that state 1 has occurred strictly lowers the Sector B individual's payoff as $\Delta_{L}<\delta$ implies that

$$
v\left(w_{B}\right)+r_{A 2}-\delta<v\left(w_{B}\right)+r_{B 2}
$$

Announcing state 3 or state 4 has occurred in state 2 (or state 2 or 4 in state 3 ; or state 2 or 3 in state 4 ) leaves the investment strategy unaltered and therefore the Sector $B$ individual's payoff. It follows that the most informative message sequence which can be sustained in equilibrium is $m_{j}=j$ for $j=1, . ., 4$. 


\section{Proof of Lemma 1}

With incomplete information and $\gamma=1$, a sector B individual's optimal investment choice solves

$$
\begin{gathered}
\widetilde{K}_{B}\left(q ;\left\{t_{1 j}, T_{1 j}\right\}_{j=1}^{4}\right)= \\
\underset{k \in\{0,1\}}{\arg \max } \sum_{j=1}^{4} q_{j}\left(v\left(\left(1-t_{1 j}\right) w_{B}\right)+\left(1-t_{1 j}\right)\left[r_{A j} k_{i}+r_{B j}\left(1-k_{i}\right)\right]-\delta k_{i}+T_{1 j}\right)
\end{gathered}
$$

We first show that $\widehat{K}_{B}(1, q)>\widehat{K}_{B}\left(1, q^{\prime}\right)$ implies $\widehat{K}_{A}(1, q)=1$. Let $\phi_{j}^{B}(\xi)=$ $\sum_{j=1}^{4} \xi_{j}\left(v\left(\left(1-t_{1 j}\right) w_{B}\right)+T_{1 j}+r_{B j}\right)$ and define

$$
\bar{V}^{B}(\xi)=\phi_{j}^{B}(\xi)+\sum_{j=1}^{4} \xi_{j}\left(1-t_{1 j}\right)\left[\left(r_{A j}-r_{B j}\right) k_{i}\right]-\delta k_{i}
$$

to be a sector $B$ individual's expected utility with probability vector $\xi$. Now let $\left(q, q^{\prime}\right)$ be such that $\widehat{K}_{B}(1, q)>\widehat{K}_{B}\left(1, q^{\prime}\right)$. This requires that

$$
\sum_{j=1}^{4} q_{j}\left(1-t_{1 j}\right)\left[\left(r_{A j}-r_{B j}\right)\right]-\delta>0
$$

and

$$
\sum_{j=1}^{4} q_{j}^{\prime}\left(1-t_{1 j}\right)\left[\left(r_{A j}-r_{B j}\right)\right]-\delta<0,
$$

which implies that:

$$
\sum_{j=1}^{4} q_{j}\left(1-t_{1 j}\right)\left[\left(r_{A j}-r_{B j}\right)\right]>\delta>\sum_{j=1}^{4} q_{j}^{\prime}\left(1-t_{1 j}\right)\left[\left(r_{A j}-r_{B j}\right)\right] .
$$

A sector A individual's expected utility can be written as

$$
\bar{V}^{A}=\phi_{j}^{A}(\xi)-\delta+\sum_{j=1}^{4} q_{j}\left(1-t_{1 j}\right)\left[\left(r_{A j}-r_{B j}\right) k_{i}\right]+\delta k_{i}
$$

Observe that $\sum_{j=1}^{4} q_{j}\left(1-t_{1 j}\right)\left[\left(r_{A j}-r_{B j}\right)\right]>\delta$ implies $\widehat{K}_{A}(1, q)=1$ as claimed. 
To complete the proof, we show equilibrium messages such that $q\left(m_{1}^{*}, p, \sigma\right)=$ $q$ and $q\left(m_{2}^{*}, p, \sigma\right)=q^{\prime}$ are not possible. Consider the the policymakers payoff in state 2 when $\gamma=1$. That is, the policymaker maximises a Sector A individual's payoff such that

$$
\begin{aligned}
\widehat{G}_{2}(1, \xi)= & v\left(\left(1-t_{12}(\widehat{K}(1, \xi))\right) w_{A}\right)+ \\
& \left(1-t_{12}(\widehat{K}(1, \xi))\right)\left[r_{A 2} \widehat{K}_{A}(1, \xi)+r_{B 2}\left(1-\widehat{K}_{A}(1, \xi)\right)\right] \\
& -\delta\left(1-\widehat{K}_{A}(1, \xi)\right)+T_{12}(\widehat{K}(1, \xi))
\end{aligned}
$$

We will show that $\widehat{G}_{2}(1, q)>\widehat{G}_{2}\left(1, q^{\prime}\right)$. There are two cases to consider. First, consider the case where $\widehat{K}_{A}\left(1, q^{\prime}\right)=1$. Then $t_{12}(\widehat{K}(1, q))=\bar{t}(0)>$ $t_{12}\left(\widehat{K}\left(1, q^{\prime}\right)\right)=\bar{t}\left(-\left(1-\pi_{A}\right) \Delta_{L}\right)$. Hence, we have

$$
\begin{aligned}
& \widehat{G}_{2}(1, q)=\quad v\left((1-\bar{t}(0)) w_{A}\right)+(1-\bar{t}(0)) r_{A 2} \\
& +\bar{t}(0)\left[\pi_{A} w_{A} l_{A}^{*}\left((1-\bar{t}(0)) w_{A}\right)+\left(1-\pi_{A}\right) w_{B} l_{B}^{*}\left((1-\bar{t}(0)) w_{B}\right)\right] \\
& \leq \\
& v\left(\left(1-\bar{t}\left(-\left(1-\pi_{A}\right) \Delta_{L}\right)\right) w_{A}\right)+\left(1-\bar{t}\left(-\left(1-\pi_{A}\right) \Delta_{L}\right)\right) r_{A 2} \\
& +\bar{t}\left(-\left(1-\pi_{A}\right) \Delta_{L}\right)\left[\pi_{A} w_{A} l_{A}^{*}\left(\left(1-\bar{t}\left(-\left(1-\pi_{A}\right) \Delta_{L}\right)\right) w_{A}\right)\right. \\
& \left.+\left(1-\pi_{A}\right) w_{B} l_{B}^{*}\left(\left(1-\bar{t}\left(-\left(1-\pi_{A}\right) \Delta_{L}\right)\right) w_{B}\right)\right] \\
& < \\
& v\left(\left(1-\bar{t}\left(-\left(1-\pi_{A}\right) \Delta_{L}\right)\right) w_{A}\right)+\left(1-\bar{t}\left(-\left(1-\pi_{A}\right) \Delta_{L}\right)\right) r_{A 2} \\
& +\bar{t}\left(-\left(1-\pi_{A}\right) \Delta_{L}\right)\left[\pi_{A} w_{A} l_{A}^{*}\left(\left(1-\bar{t}\left(-\left(1-\pi_{A}\right) \Delta_{L}\right)\right) w_{A}\right)\right. \\
& \left.+\left(1-\pi_{A}\right) w_{B} l_{B}^{*}\left(\left(1-\bar{t}\left(-\left(1-\pi_{A}\right) \Delta_{L}\right)\right) w_{B}\right)-\left(1-\pi_{A}\right) \Delta_{L}\right] \\
& =\widehat{G}_{2}\left(1, q^{\prime}\right)
\end{aligned}
$$

Thus $\widehat{G}_{2}(1, q)>\widehat{G}_{2}\left(1, q^{\prime}\right)$. Now consider the case where $\widehat{K}_{A}\left(1, q^{\prime}\right)=0$. Then $t_{12}(\widehat{K}(1, q))=\bar{t}(0)=t_{12}\left(\widehat{K}\left(1, q^{\prime}\right)\right)$. Then we have

$$
\begin{aligned}
& \widehat{G}_{2}(1, q)=\quad v\left((1-\bar{t}(0)) w_{A}\right)+(1-\bar{t}(0)) r_{A 2} \\
& +\bar{t}(0)\left[\pi_{A} w_{A} l_{A}^{*}\left((1-\bar{t}(0)) w_{A}\right)+\left(1-\pi_{A}\right) w_{B} l_{B}^{*}\left((1-\bar{t}(0)) w_{B}\right)\right] \\
& < \\
& v\left((1-\bar{t}(0)) w_{A}\right)+\left(1-\bar{t}(0) r_{B 2}-\delta\right. \\
& +\bar{t}(0)\left[\pi_{A} w_{A} l_{A}^{*}\left((1-\bar{t}(0)) w_{A}\right)+\left(1-\pi_{A}\right) w_{B} l_{B}^{*}\left((1-\bar{t}(0)) w_{B}\right)\right] \\
& =\widehat{G}_{2}\left(1, q^{\prime}\right)
\end{aligned}
$$


Thus $\widehat{G}_{2}(1, q)>\widehat{G}_{2}\left(1, q^{\prime}\right)$ in this case too.

Now suppose that $\left(m_{1}^{*}, m_{2}^{*}\right)$ exist such that $q\left(m_{1}^{*}, p, \sigma\right)=q$ and $q\left(m_{2}^{*}, p, \sigma\right)=$ $q^{\prime}$. Then, for all $\sigma$,

$$
\widehat{G}_{2}\left(1, q\left(m_{1}^{*}, p ; \sigma\right)\right)>\widehat{G}_{2}\left(1, q\left(m_{2}^{*}, p ; \sigma\right)\right)=\underset{m \in \mathcal{M}}{\arg \max }\left\{\widehat{G}_{2}(1, q(m, p ; \sigma))\right\}
$$

- a contradiction. This proves the lemma.

Proof of Proposition 4: We construct beliefs such that the equilibrium is as described. Suppose that these are

$$
\begin{aligned}
\sigma_{j}\left(m_{j}\right) & =1 \text { when } m_{j}=j \text { and } j=3,4 \\
\sigma_{j}\left(m_{j}\right) & =\frac{1}{2} \text { when } m_{j}=\{1 \cup 2\} \text { and } j=1,2 \\
\sigma_{k}\left(m_{j}\right) & =\frac{1}{4} \text { for all } k \text { and for other } m_{j} \in \mathcal{M}
\end{aligned}
$$

We now need to show three things: that the posited investment strategies form an investment equilibrium, that the redistribution strategies and messages are optimal for a policy maker with $\gamma=1 . \gamma=1$ implies that the policymaker maximises a Sector $A$ individual's payoff. Given the beliefs, on hearing the message that either state 1 or state 2 has occurred, investors update such that

$$
q_{1}(1 \cup 2)=\frac{p_{1}}{p_{1}+p_{2}} \text { and } q_{2}(1 \cup 2)=\frac{p_{2}}{p_{1}+p_{2}}
$$

Now consider the decision to invest in sector $A$ by sector $B$ individuals. They invest in sector $A$ general if and only if $\sum_{j=1}^{4} q_{j}\left(1-t_{j}\right)\left[\left(r_{A j}-r_{B j}\right)\right]>\delta$. When the message is $1 \cup 2$ this boils down to $(1-\bar{t}(0))\left[p_{1} \Delta_{H}+p_{2} \Delta_{L}\right]>$ $\left(p_{1}+p_{2}\right) \delta$ which is the condition in the Proposition. States 3 and 4 are fully revealed in the posited equilibrium bringing forth full information investment strategies. Hence, we have shown that the investment strategies with these beliefs are:

$$
\begin{aligned}
& \widehat{K}_{A}\left(1, q\left(m_{j}, \sigma\right)\right)=1, \text { for } j=1,2,3, \text { and } \widehat{K}_{A}(1, q(4, \sigma))=0 \\
& \widehat{K}_{B}\left(1, q\left(m_{j}, \sigma\right)\right)=1 \text {, for } j=1,2 \text { and } \widehat{K}_{B}\left(1, q\left(m_{j}, \sigma\right)\right)=0 \text {, for } j=3,4 .
\end{aligned}
$$

Turning now to redistribution, it is easy to check that the redistribution strategies which follow (5) are

$$
\begin{aligned}
\left(t_{j}, T_{j}\right) & =(\bar{t}(0), \bar{T}(0)) \text { for } j=1,2,4 \\
\left(t_{3}, T_{3}\right) & =\left(\bar{t}\left(\left(1-\pi_{A}\right) \Delta_{L}\right), \bar{T}\left(\left(1-\pi_{A}\right) \Delta_{L}\right)\right)
\end{aligned}
$$


The final step must show that the messages posited are a best response. We need to show that no off-the-equilibrium-path message is preferred and that no deviation to another equilibrium message is optimal for the policy maker in any state. First recall, that from Assumption 4, any deviation to any other message results in an investment strategy where each individual always invests in their own sector. Using this, we can show that the policy maker will never prefer to deviate to such a message. In states 1 and 2, this follows since

$$
\begin{aligned}
& v\left((1-\bar{t}(0)) w_{A}\right)+(1-\bar{t}(0)) r_{A k} \\
& +\bar{t}(0)\left[\pi_{A} w_{A} l_{A}^{*}\left((1-\bar{t}(0)) w_{A}\right)+\left(1-\pi_{A}\right) w_{B} l_{B}^{*}\left((1-\bar{t}(0)) w_{B}\right)\right] \\
\geq & v\left(\left(1-\bar{t}\left(-\left(1-\pi_{A}\right) \Delta_{j}\right)\right) w_{A}\right)+\left(1-\bar{t}\left(-\left(1-\pi_{A}\right) \Delta_{j}\right)\right) r_{A k} \\
& +\bar{t}\left(-\left(1-\pi_{A}\right) \Delta_{j}\right)\left[\pi_{A} w_{A} l_{A}^{*}\left(\left(1-\bar{t}\left(-\left(1-\pi_{A}\right) \Delta_{j}\right)\right) w_{A}\right)\right. \\
& \left.+\left(1-\pi_{A}\right) w_{B} l_{B}^{*}\left(\left(1-\bar{t}\left(-\left(1-\pi_{A}\right) \Delta_{j}\right)\right) w_{B}\right)\right] \\
> & \\
& v\left(\left(1-\bar{t}\left(-\left(1-\pi_{A}\right) \Delta_{j}\right)\right) w_{A}\right)+\left(1-\bar{t}\left(-\left(1-\pi_{A}\right) \Delta_{j}\right)\right) r_{A k} \\
& +\bar{t}\left(-\left(1-\pi_{A}\right) \Delta_{j}\right)\left[\pi_{A} w_{A} l_{A}^{*}\left(\left(1-\bar{t}\left(-\left(1-\pi_{A}\right) \Delta_{j}\right)\right) w_{A}\right)\right. \\
& \left.+\left(1-\pi_{A}\right) w_{B} l_{B}^{*}\left(\left(1-\bar{t}\left(-\left(1-\pi_{A}\right) \Delta_{j}\right)\right) w_{B}\right)-\left(1-\pi_{A}\right) \Delta_{j}\right],
\end{aligned}
$$

where the first expression is a Sector A individual's payoff along the equilibrium path and the last is payoff after the posited deviation when the state is either $1(k=1$ and $j=H)$ or $2(k=2$ and $j=L)$. In state 3 , it is clear that the policy maker is indifferent between this message and an uninformative one. In state 4 , he prefers to announce that state 4 has occurred since

$$
\begin{aligned}
& v\left((1-\bar{t}(0)) w_{A}\right)+(1-\bar{t}(0)) r_{B 4}-\delta \\
& +\bar{t}(0)\left[\pi_{A} w_{A} l_{A}^{*}\left((1-\bar{t}(0)) w_{A}\right)+\left(1-\pi_{A}\right) w_{B} l_{B}^{*}\left((1-\bar{t}(0)) w_{B}\right)\right] \\
& v\left(\left(1-\bar{t}\left(\left(1-\pi_{A}\right) \Delta_{H}\right)\right) w_{A}\right)+\left(1-\bar{t}\left(\left(1-\pi_{A}\right) \Delta_{H}\right)\right) r_{A 4} \\
& +\bar{t}\left(\left(1-\pi_{A}\right) \Delta_{H}\right)\left[\pi_{A} w_{A} l_{A}^{*}\left(\left(1-\bar{t}\left(\left(1-\pi_{A}\right) \Delta_{H}\right)\right) w_{A}\right)\right. \\
& \left.+\left(1-\pi_{A}\right) w_{B} l_{B}^{*}\left(\left(1-\bar{t}\left(\left(1-\pi_{A}\right) \Delta_{H}\right)\right) w_{B}\right)+\Delta_{H}\right] .
\end{aligned}
$$

Now consider incentives to deviate to other on-the-equilibrium-path messages. In states 1 and 2, deviating to announce that state 3 has occurred 
follows the same logic as a deviation to a message interpreted as uninformative as it results in the same investment decisions as in the case of uninformed investing. Thus the inequality in (12) is relevant. For a deviation to announce state 4 in states 1 or 2 , it is clear that this is undesirable since redistribution is the same and $(1-\bar{t}(0)) r_{B 4}-\delta>(1-\bar{t}(0)) r_{A 4}$. Now consider state 3 . A deviation to the message that state 1 or 2 has occurred is not optimal since

$$
\begin{aligned}
& v\left((1-\bar{t}(0)) w_{A}\right)+(1-\bar{t}(0)) r_{A 3} \\
& +\bar{t}(0)\left[\pi_{A} w_{A} l_{A}^{*}\left((1-\bar{t}(0)) w_{A}\right)+\left(1-\pi_{A}\right) w_{B} l_{B}^{*}\left((1-\bar{t}(0)) w_{B}\right)\right] \\
< & v\left(\left(1-\bar{t}\left(\left(1-\pi_{A}\right) \Delta_{L}\right)\right) w_{A}\right)+\left(1-\bar{t}\left(\left(1-\pi_{A}\right) \Delta_{L}\right)\right) r_{A 3} \\
& +\bar{t}\left(\left(1-\pi_{A}\right) \Delta_{L}\right)\left[\pi_{A} w_{A} l_{A}^{*}\left(\left(1-\bar{t}\left(\left(1-\pi_{A}\right) \Delta_{L}\right)\right) w_{A}\right)\right. \\
& \left.+\left(1-\pi_{A}\right) w_{B} l_{B}^{*}\left(\left(1-\bar{t}\left(\left(1-\pi_{A}\right) \Delta_{L}\right)\right) w_{B}\right)+\Delta_{L}\right] .
\end{aligned}
$$

A deviation to announce state 4 in state 3 is not desirable since $(1-\bar{t}(0)) r_{B 3}-$ $\delta<(1-\bar{t}(0)) r_{A 3}$ and the level of redistribution falls from $\bar{t}\left(\left(1-\pi_{A}\right) \Delta_{L}\right)$ to $\bar{t}(0)$. Finally, we consider state 4 . A deviation to announcing state 3 yields the same investment profile as the uninformative case which we have already shown to be undesirable. Now consider a deviation to announcing that state 1 or 2 has occurred. This is not desirable since redistribution is unchanged and $(1-\bar{t}(0)) r_{B 4}-\delta>(1-\bar{t}(0)) r_{A 4}$.

Proof of Proposition 5: The method of proof is essentially the same as proposition 4. The beliefs that we described in that Proposition can also support the equilibrium in this case. The main difference from proposition 4 is that as $(1-\bar{t}(0))\left[p_{1} \Delta_{H}+p_{2} \Delta_{L}\right]<\left(p_{1}+p_{2}\right) \delta$ when $m_{j}=\{1 \cup 2\}$ and $j=1,2$ sector $\mathrm{B}$ investors continue to invest in their own sector. Therefore, the equilibrium investment profile now is

$$
\begin{aligned}
& \widehat{K}_{A}\left(1, q\left(m_{j}, \sigma\right)\right)=1, \text { for } j=1,2,3 \text { and } \widehat{K}_{A}\left(1, q\left(m_{4}, \sigma\right)\right)=0 \\
& \widehat{K}_{B}\left(1, q\left(m_{j}, \sigma\right)\right)=0, \text { for } j=1,2,3,4 .
\end{aligned}
$$

and the corresponding tax profile:

$$
\left(t_{1}, T_{1}\right)=\left(\bar{t}\left(-\left(1-\pi_{A}\right) \Delta_{H}\right), \bar{T}\left(-\left(1-\pi_{A}\right) \Delta_{H}\right)\right)
$$




$$
\begin{aligned}
\left(t_{2}, T_{2}\right) & =\left(\bar{t}\left(-\left(1-\pi_{A}\right) \Delta_{L}\right), \bar{T}\left(-\left(1-\pi_{A}\right) \Delta_{L}\right)\right) \\
\left(t_{3}, T_{3}\right) & =\left(\bar{t}\left(\left(1-\pi_{A}\right) \Delta_{L}\right), \bar{T}\left(\left(1-\pi_{A}\right) \Delta_{L}\right)\right) \\
\left(t_{4}, T_{4}\right) & =(\bar{t}(0), \bar{T}(0))
\end{aligned}
$$

We now show that the posited messages remain an equilibrium in this case by checking that the policymaker does not have an incentive to deviate to off-the-equilibrium-path messages or to other equilibrium messages. Since the investment profile in this equilibrium is the same as in the case where no information is passed except in state 4 , the policy maker is indifferent between this and an uninformative equilibrium in all other states.

In states 1, 2 and 3 the investment strategies and therefore the level of redistribution are unaffected by a deviation to an off-the-equilibrium-path (uninformative) message and therefore the policymaker is indifferent between sending the equilibrium messages and any other. In state 4 , the policymaker strictly prefers revealing the state as

$$
\begin{aligned}
& v\left((1-\bar{t}(0)) w_{A}\right)+(1-\bar{t}(0)) r_{B 4}-\delta \\
& +\bar{t}(0)\left[\pi_{A} w_{A} l_{A}^{*}\left((1-\bar{t}(0)) w_{A}\right)+\left(1-\pi_{A}\right) w_{B} l_{B}^{*}\left((1-\bar{t}(0)) w_{B}\right)\right] \\
& v\left(\left(1-\bar{t}\left(\left(1-\pi_{A}\right) \Delta_{H}\right)\right) w_{A}\right)+\left(1-\bar{t}\left(\left(1-\pi_{A}\right) \Delta_{H}\right)\right) r_{A 4} \\
& +\bar{t}\left(\left(1-\pi_{A}\right) \Delta_{H}\right)\left[\pi_{A} w_{A} l_{A}^{*}\left(\left(1-\bar{t}\left(\left(1-\pi_{A}\right) \Delta_{H}\right)\right) w_{A}\right)\right. \\
& \left.+\left(1-\pi_{A}\right) w_{B} l_{B}^{*}\left(\left(1-\bar{t}\left(\left(1-\pi_{A}\right) \Delta_{H}\right)\right) w_{B}\right)+\Delta_{H}\right] .
\end{aligned}
$$

Now consider the incentives to deviate to other on-the-equilibrium-path messages. In states 1 and 2 announcing state 3 has occurred leaves investment strategies unaffected. The policymaker is therefore indifferent between the messages announcing that the state is either 1 or 2 and that state 3 has occurred. However, in states 1 and 2 a deviation to announcing state 4 is strictly undesirable as redistribution is unchanged but $(1-\bar{t}(0)) r_{B k}-\delta<$ $(1-\bar{t}(0)) r_{A k}$ for $k=1,2$. In state 3 announcing state 1 and 2 has occurred leaves investment strategies unaffected. The policymaker is therefore indifferent between the messages $(1 \cup 2)$ and $(3)$. However announcing state 4 is strictly undesirable as redistribution is unchanged but $(1-\bar{t}(0)) r_{B 3}-\delta<$ $(1-\bar{t}(0)) r_{A 3}$. In state 4 , a deviation to announcing states 1 and 2 or state 3 yields the same investment profile as in the uninformative case which we have already shown is undesirable. 
Proof of Proposition 6: It is easy to prove that full information is dominant state by state. In states 2,3 and 4 , the redistribution, investment strategies are the same in the full information and incomplete information case - they are those given in Proposition 5. Hence, the ex post payoffs in both sectors are the same in these states. In state 1 , however, sector $B$ individuals will invest at the tax rate $\bar{t}\left(-\left(1-\pi_{A}\right) \Delta_{H}\right)<\bar{t}(0)$ by assumption 2. This generates a Pareto improvement in that state since this raises mean income. Hence, for a given tax rate, sector $A$ and sector $B$ individuals gain if $\bar{t}\left(-\left(1-\pi_{A}\right) \Delta_{H}\right)>0$. Otherwise sector $\mathrm{B}$ individuals gain and sector $\mathrm{A}$ individuals are as well off.

Proof of Proposition 7: To see this, observe that in investment and redistributive strategies will be identical under incomplete and full information in states 1,3 , and 4 . Hence, the only possible difference arises in state 2 . Under full information, the sector $B$ individuals will choose not to invest in sector $A$. This makes sector $B$ individuals better off and sector $A$ individuals worse off. Hence, to generate a Pareto improvement a variation in the tax rate must be found that compensates the sector $A$ individuals. It is easy to see that this is impossible. Let

$H^{A}(t)=v\left((1-t) w_{A}\right)+t\left[\pi_{A} w_{A} l_{A}^{*}\left((1-t) w_{A}\right)+\left(1-\pi_{A}\right) w_{B} l_{B}^{*}\left((1-t) w_{B}\right)\right]$.

It is clear that $\bar{t}(0)$ maximizes $H^{A}(t)$ for $t \in[0,1]$. Hence,

$$
H^{A}(\bar{t}(0))>H^{A}(t)-t \Delta_{L}\left(1-\pi_{A}\right)
$$

for all $t \in[0,1]$. But $H^{A}(\bar{t}(0))+\Delta_{L}$ is a sector $A$ individual's state 2 payoff under incomplete information and $H^{A}(t)+\Delta_{L}-t \Delta_{L}\left(1-\pi_{A}\right)$ is their state 2 payoff under full information. Hence, it is impossible to compensate sector $A$ individuals for the move to full information 